\title{
EL ALTO CHOCO EN EL SIGLO XVI
}

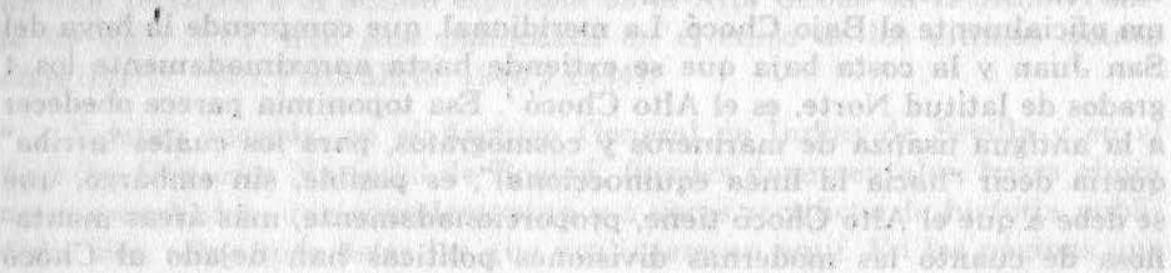

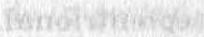

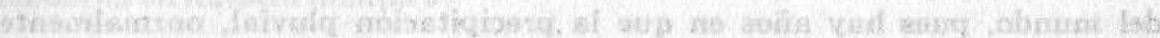

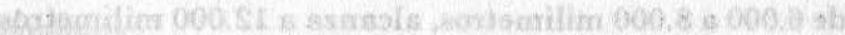

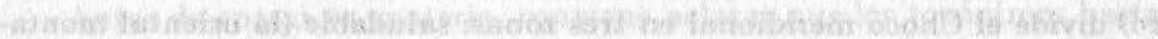

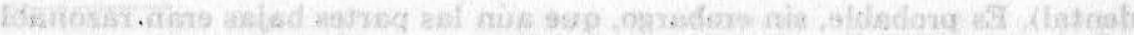

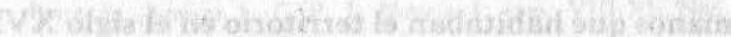

Kathleen Romoli 
La faja occidental del territorio colombiano que se denomina El Chocó, se divide en dos a la altura del Istmo de San Pablo y la de Cabo Corrientes. La parte septentrional - la cuenca del Atrato y la costa accidentada que de Corrientes se prolonga hasta la frontera con Panamá- se llama oficialmente el Bajo Chocó. La meridional, que comprende la hoya del San Juan y la costa baja que se extiende hasta aproximadamente los 4 grados de latitud Norte, es el Alto Chocó ${ }^{1}$. Esa toponimia parece obedecer a la antigua usanza de marineros y cosmógrafos, para los cuales "arriba" quería decir "hacia la línea equinoccional"; es posible, sin embargo, que se debe a que el Alto Chocó tiene, proporcionadamente, más áreas montanosa de cuanto las modernas divisiones políticas han dejado al Chocó septentrional.

En razón de la geografía física, determinante de los límites en el siglo XVI, el Alto Chocó abarcaría unos 18.000 kilómetros cuadrados, ya que ncluye los valles del Calima y del Garrapatas superior, hoy agregados al Departamento del Valle del Cauca, y el triángulo de tierra en que nacen los brazos cabeceras del San Juan, actualmente del Departamento de Risaralda. La mayor parte de esa extensión está cubierta de selva alta y tupida, que prospera en un clima tropical que es uno de los más húmedos del mundo, pues hay años en que la precipitación pluvial, normalmente de 6.000 a 8.000 milímetros, alcanza a 12.000 milímetros.

Un estudio oficial (Geografía Económica de Colombia, Tomo VI: Chocó) divide el Chocó meridional en tres zonas: saludable (la oriental montañosa), insalubre higienizable (la central) e insalubre permanente (la occidental). Es probable, sin embargo, que aún las partes bajas eran razonablemente saludables antes de que los europeos y los africanos vinieran con sus enfermedades; en ellas se asentaba más de la mitad de los grupos humanos que habitaban el territorio en el siglo XVI.

Dos de estos grupos aún subsisten con los mismos gentilicios que en aquel entonces. Pero, las fuentes inéditas en que se inspiran los presentes apuntes, nombran a otras veinte tribus distintas y autónomas, radicadas en territorio surchocoano al tiempo del primer ensayo de colonización es-

1 El término "Bajo Chocó" ha tenido diferentes aplicaciones, incluso aquella errónea al litoral que se extiende al Sur de Buenaventura. En la monografia Chocó, publicada por la Contraloría de la Re. pública (Tomo VI de la Geografia Económica de Colombia), p. 9-10, se precisa que el Alto Chocó es la parte del territorio que está al Sur del Istmo de San Pablo. pañola. En las páginas que siguen, se verá cuáles eran esas colectividades desaparecidas, y cuáles los sectores en que señoreaban.

\section{Las Fuentes Documentales}

Son conocidos los relatos que hacen los cronistas Juan de Castellanos y Pedro Simón del primer intento de colonización en el Chocó meridional. Castellanos da el resalto heroico propio de la epopeya rimada, los hechos salientes de los años $1573-1790^{2}$, Simón refiere esos mismos acontecimientos (tomados principalmente de Castellanos) y más los de la década siguiente, acerca de los cuales estaba particularmente bien informado ${ }^{3}$. Hay también la relación de la gesta de Jorge Robledo, redactada en Octubre de $1540^{4}$, en que se cuenta el primer contacto español con los indios chocoes, y Cieza de León reporta algunas escuetas noticias al respecto, oídas al parecer, de conquistadores de Anserma ${ }^{5}$. Unos interesantes documentos relativos a la acción española en el Alto Chocó en el último cuarto de siglo XVI, han sido publicados en el curso de los últimos treinta años (HDC, 1945; Piedrahíta, 1945 y 1954).

Existen además, en el Archivo General de Indias de Sevilla y en el Archivo Histórico Nacional de Bogotá, fuentes documentales, hasta ahora no aprovechadas, que complementan y a veces rectifican la historia publicada. Son sobre todo éstas las que nos interesan aquí. En las páginas que siguen reportamos varios de esos documentos, entre ellos tres de importancia muy especial. Son estos: un mapa etnográfico del Chocó dibujado por el ex gobernador Melchior de Salazar en el año 1596; la Descriçión de la tierra del mismo Salazar, compuesto para acompañar al mapa ${ }^{6}$, y la relación de la primera expedición de conquista y colonización del Alto Chocó de 1573, hecha por el testigo presencial Fray Martín de Medrano de la Orden de Santo Domingo ${ }^{7}$. Reproducimos los escritos en copias fieles, sin arreglos modernizantes; el mapa se traduce en términos de la cartografia moderna en nuestra lámina 3.

\section{Sobre algunos topónimos}

Antes de entrar en materia, conviene aclarar que los topónimos hasta aquí mencionados, no son los que corrían en los tiempos del descubrimien-

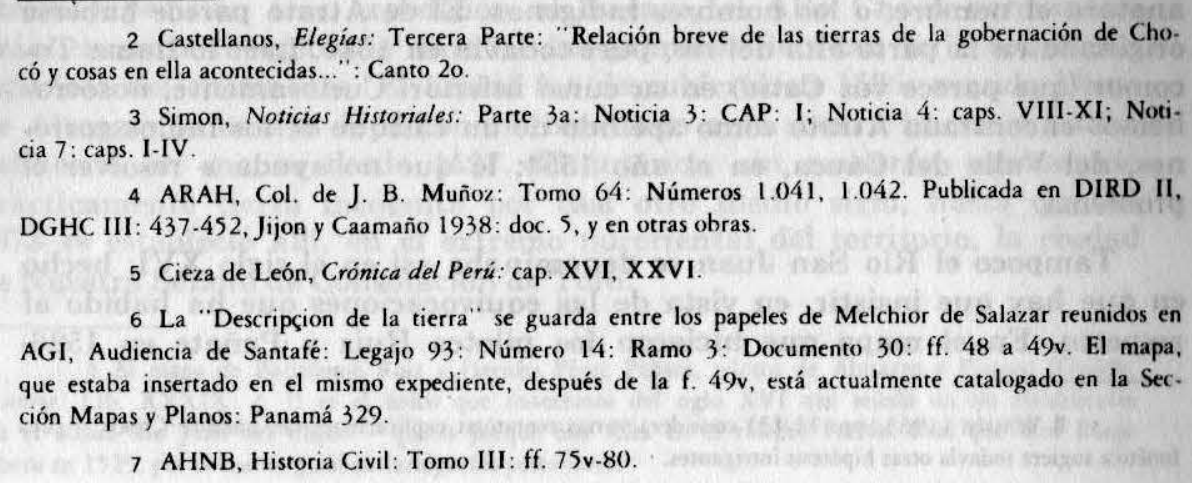


Mucho se ha discutido sobre el origen y el significado de esta palabra. Una hipótesis ha sido que deriva de Coguo, apellido de un cacique de la costa mencionado por Oviedo (Historia, XXIX: xxiii); pero resulta que tal cacique, si existió, debió ser de una región distinta (Id., XL: iii). Otra conjetura es que el nombre viene de la voz emberá chóko, olla; el significado sería "la gente de las ollas", los alfareros ${ }^{8}$. Sin embargo, nada en las fuentes sugiere que los indios chocoes tenían semejante fama, y en todo caso parece que faltaría al vocablo un sufijo del valor de "gente". En ese campo de la especulación, teniendo en cuenta la más o menos lejana proveniencia amazónica de los Chocó y la propensidad de los pueblos indios de auto-denominarse "los Hombres", tal vez se debería considerar el vocablo yuri tschokó, hombre (Martius, transcrito por Ortiz 1965: p. 235).

Sea como fuera el significado pristino de la palabra, la aplicación original de ella como topónimo está bien clara en nuestras fuentes.

El nombre Chocó cuando aparece por primera vez en la relación de 1540 ya mencionada, era el de una tierra tribal situada al Oeste del distrito de Santa Ana de los Caballeros (luego llamado Anserma), del cual le separaba la provincia fronteriza de Sima. Veintiseis o veintiocho años más tarde, cuando se quería aprovechar el hecho de que vecinos de Anserma habían descubierto a este Chocó, los interesados empezaron a extender el topónimo a todo el territorio occidental entre Buenaventura y el Istmo. Pero aún después de generalizarse este sentido ampliado, quedó perfectamente entendido que el Chocó en sentido estricto, el primitivo y auténtico, era la comarca circunscrita que estaba entre el alto Río Atrato (el "río de Darién") y el alto San Juan (el Tamana del mapa e informe de Salazar). Este Chocó nuclear limitaba al Norte con la provincia de los Citarabirá y al Sur con las de los Yngará y los Tootuma y tal vez con los Cirambirá; al Oeste confinaba con las tribus del Baudó y al Este con Sima, Tatape y la Cordillera alta.

El Río Atrato no se llamaba así antes del siglo XVII. El descubridor Núñez de Balboa lo bautizó San Juan; más tarde, los españoles lo llamaban el río grande del Darién, o sencillamente Río Darién, sin que nadie anotara el nombre, o los nombres indígenas. El de Atrato parece haberse originado en la parte alta del río, pues todavía en 1640, Laet lo llama Tocomor (que parece voz Catío) en su curso inferior. Curiosamente, nosotros hemos encontrado Atrato como apellido de un cacique de los indios gorrones, del Valle del Cauca, en el año 1554; lo que no ayuda a resolver el problema.

Tampoco el Río San Juan se denominaba así en el siglo XVI: hecho en que hay que insistir, en vista de las equivocaciones que ha habido al respecto. En el mapa que hicieron los pilotos Ruiz y Peñate en 1526-

1627, el actual San Juan del Chocó está rotulado, "Río Baxo"9; el adelantado Pascual de Andagoya, quien no vió sino la boca, lo refiere sin nombre como "un río grande", en una carta de 1540. Una vez identifica. dos los indios de su curso inferior, se le llamó en conformidad, "río de los noanamas", nombre que persistió hasta bien entrado el siglo XVII, cuando ya se había dado el de San Juan a la parte superior del río. Salazar, que en 1596 lo llama Tamana (MS I y mapa), lo refiere doce años más tarde como el río del Chocó y explica que era llamado "de Noanamas" desde la boca del Tuturrupí (hoy Sipí) por abajo, y "San Juan" en la parte arriba del Tuturrupisipí (HDC: Doc. IX).

Lo importante por aclarar es que no era éste el Río de San Juan que dio título a la gobernación concedida a Pascual de Andagoya en 1538. El río de San Juan de Andagoya - que era el de Almagro y de Pizarro en 1525 y 1526, de Payo Romero y Juan de Andagoya en 1541-1543, de una serie de efimeras fundaciones emprendidas desde Popayán entre 1542 y 1572, y de todos los mapas y descripciones hechas de esas costas en el siglo XVI- era el actual San Juan de Micay, que corre por el Departamento del Cauca. Como a pesar de lo abundante y unánime de la documentación al respecto, se sigue confundiendo el San Juan original con su tardío homónimo surchocoano, hay que recalcar que con relación a la costa colombiana del Pacífico, ninguna referencia geográfica, histórica o etnográfica al río de San Juan y sus provincias, anterior al siglo XVII, tiene que ver con el Chocó.

Los otros topónimos registrados en las fuentes, se explicarán a su tiempo. Quizás no sobre decir aquí, sin embargo, que el término "las Barbacoas", que se encuentra en escritos antiguos sobre el Chocó, no era por entonces propiamente toponímico y menos, gentilicio o calificación linguística. Se refería solamente al tipo de construcción de las casas, que aquí como en otras regiones de excesiva humedad, eran abiertas por los lados y elevadas sobre altos postes a manera de grandes barbacoas techadas.

\section{Descubrimiento}

A diferencia del Chocó septentrional, en donde el espejismo de la ciudad de Dabaybe, con sus fabulosos palacios y templo de oro macizo, atraía expedición tras expedición al fracaso, el Alto Chocó permaneció prácticamente inexplorado durante las primeras décadas de la ocupación española del continente. El litoral fue descubierto en 1525, cuando Diego de Almagro lo barajó de río en río buscando a su socio Pizarro, y estaba delineado en mapas desde 1527. El interior, sin embargo, permaneció prácticamente tierra incógnita por casi otro medio siglo, hasta que en 1573 se estableció allí, en el extremo nororiental del territorio, la ciudad de Nuestra Señora de Consolación de Toro.

9 El mapa de Bartolomé Ruiz y Hernán Pérez Peñate, pilotos de Almagro y Pizarro (Oviedo, Historia: Lib. XXXIX: c. I) es el único que conocemos del siglo XVI que señala un río identificable con el actual San Juan del Chocó - quizás porque éste falta en el célebre Patrón Real que hizo Diego Ribero en 1529, por el cual se guiaban cartógrafos posteriores. 
En solo tres ocasiones, hasta donde se sabe, hubo intentos anteriores a 1573 para penetrar al Alto Chocó. El primero fue en 1536, cuando Sebastián de Belalcázar envió a Juan Ladrillero a hallar, desde el valle del Cauca, un puerto de mar al otro lado de la Cordillera Occidental. Con 30 soldados, Ladrillero llegó, al parecer por el fácil camino de La Llamada, a las primeras vertientes chocoanas; averiguó lo imposible del acometido y lo inhóspito de la tierra, y luego de unas vueltas "por la altura" regresó al real ${ }^{10}$. Sin saberlo, había descubierto las provincias de los Chanco, donde cuarenta años más tarde se iba a fundar la ciudad de Cáceres.

El segundo ensayo de penetración se hizo desde Anserma en los últimos de 1539, por orden de Jorge Robledo. Cincuenta hombres al mando del capitán Gómez Hernández cruzaron la Cordillera por la depresión que lleva a las cabeceras del Río San Juan, siguiendo por trochas indias hasta encontrar un río caudaloso que creían con razón, ser parte del Río Darién y que sin duda era el Andágueda. En estos parajes, hallaron al pie de una loma un caserío chocó cuyos moradores ofrecieron tan recia resistencia que los españoles tuvieron que salir de estampía por la vía del regreso, dejando uno o dos muertos, más dos heridos que lograron volver por sus propios medios. Cuarenta y cinco días después de partida, la compañía estaba nuevamente en Anserma 11

La tercera vez que se vió algo más que la costa, fue en 1540, cuando dos bergantines de la armada de Andagoya, entonces surgida en la isla de Palmas, subieron el Río San Juan casi hasta Munguidó, en el curso de los tanteos que hacían para encontrar un buen puerto de desembarco. Regresaron al encontrar indios hostiles, al parecer sin haber tomado tierra ${ }^{12}$ - Con esto, termina la corta lista de las entradas al Alto Chocó anteriores a 1573, ya que otras expediciones que a veces se citan como realizadas allí fueron realmente al Bajo Chocó (v.g. Gómez Hernández, Zavala), o al San Juan original, al Oeste de Popayán (Ladrillero. Delgadillo, Quintero, Bazán, etc.), o bien se frustraron antes de empezar (Cepeda, Día Sánchez de Narváez). Y desde 1500 hasta 1566, una drástica ordenanza real prohibía, bajo pena de muerte, cualquier incursión y conquista en tierras nuevas ${ }^{13}$.

\section{La primera colonización}

Derogada la ley que vedaba nuevas conquistas, el capitán Gómez Her nández se apresuró a pedir para sí la gobernación del Chocó, dando a este topónimo - al parecer, por primera vez - su máxima extensión, a todo el territorio transmontano de Buenaventura al Istmo: ensanche denominativo

10 Castellanos, op. cit.: "Historia de Popayán": Canto 4

11 "Relación del viaje que hizo el muy noble señor capitan Jorge Robledo..." ARAH, Muñoz T. 64: Núm. 1.041, 1.042. Véase también Simon, 3a: 3:I.

12 Pascual de Andagoya, carta al Rey de 15 septiembre de 1540. En Trimborn 1954: 179-196

13 Cédula real de 31 diciembre de 1549: AGI, Audiencia de Santafé: Legajo 533: Lib. I: f. que se debía a que solamente del Chocó (nuclear) el capitán tenía título
de descubridor. En España, donde fue a gestionar el asunto, Gómez Hernández tuvo pleno éxito, pero al regreso le cogió la muerte en Cartagena. No demoraron en presentarse otros candidatos, de los cuales el de mejor opción era un acaudalado vecino de Anserma, el capitán Lucas Dávila, cuyo yerno Francisco Redondo había negociado la concesión en España. En febrero de 1572, el Real Consejo refirió la propuesta a la Audiencia Real de Santa Fe, a título de consulta ${ }^{14}$

Las cosas estaban a este punto cuando el gobernador de Popayán, Don Gerónimo de Silva, otorgó al capitán Melchor de Velásquez, vecino de Buga, comisión para pacificar y poblar las provincias de los indios Chancos y Chocoes. La cédula respectiva y la Instrucción anexa fueron firmadas el 15 de octubre de 1572 , en la posada de La Balsa, mientras el gobernador estaba de viaje entre Popayán y Cali. Parece que hubo un cierto afán para que un agente de Silva fuese ya en posesión del Chocó, antes de que se concretaran las capitulaciones con Dávila.

Melchor de Velásquez (de Valdenebro, dice Ocariz), nativo de Utrera e "hidalgo notorio", tenía por entonces unos 45 años. Estaba casado con una nieta de Sebastián de Belalcázar, hija del famoso Alonso de Fuenmayor a quien Belalcázar había dejado la gobernación de Popayán en una última voluntad que no tuvo efecto. Hombre de posición y de posibles, era uno de los pretendientes a la gobernación del Chocó, pero no tenía la arrogancia de un Hernández o un Dávila, y aceptó de buena gana ser capitán general de una expedición ordenada por Silva. Organizó sin dificultades una compañía de cien hombres -o más exactamente, de noventa y cuatro hombres de armas, dos sacerdotes y dos religiosos dominicanos- con 120 caballos y todos los pertrechos y bastimentos necesarios, y en mayo de 1573, salió camino al Occidente.

Mitad de la fuerza, al mando del capitán Pedro Moriones, se encaminó desde Roldanillo a hacer una entrada punitiva a los Chanco, quienes habitaban las altas vertientes chocoanas de la cordillera desde el Río de las Vueltas hasta las cabeceras del Calima. Velásquez, con el resto de la gente, tomó un camino que subía algo más al Norte, para poner real en el río de los Chancos, afluente al Cauca que nace al Suroeste del actual Anserma Nueva. Y aquí fundó, el 3 de junio de 1573, con todas las ceremonias del caso, la ciudad de Nuestra Señora de Consolación de Toro.

El lugar de la fundación no era tierra chocoana sino un paraje de la banda izquierda del Cauca en parte ya conocida y hasta cierto punto explotada por españoles, que estaba - como lo avisó el mismo Velásquez a la Real Audiencia de Santafé- "en los términos de Cartago distrito desta Real audiencia" (MS II: ff 72-72v, 96). El acta de fundación del 3 de junio, precisa el sitio:

14 El parecer de la Audiencia está en HDC: Número VI, en donde se lo titula erradamente, capitulación

15 Copia del documento. certificada en Buga el 23 de abril de 1574, está en AHNB. Historia Givil: T. III: ff. 86-87v. Publicado en HDC: Núm. IV y por Piedrahita 1954: 27-32 
postrero dia del mes de julio [sic por junio, v, infra] pasado del año de setenta y tres se partio el dicho capitan mo velasquez con los dichos cient. onbres asi apercebidos y con ciento y beynte y dos caballos/y tardo desde el sitio del pueblo de la cibdad de toro siete leguas a la poblazon de los yngaraes diez y nueve dias todo por montanas muy cerRadas donde peresçieron los cien caballos de hambre y sed... domingo antes de la magdalena entro el dicho capitan con su gente en la probinçia de los yngaraes y con ser mas de tres myll yndios los tuvo de paz y le binyeron alli a servir todo los caçiques que avia en aquella probinçia que son siete y le sirbieron hasta Vigilia del señor santo domingo de los predicatores mas de myll yndios de las dichas probinçias de los yngaraes el descubrimiento de las provinçias de los toOtumas donde estubo el dicho capitan con su campo desde el dicho dia de santo domingo y andubo y hallo las dichas probinçias hasta otro dia de los apostoles de san simon y Judas sin benyrle undio de paz sino solo un caçique que se dize çara el qual le sirbio de yndios tamenes para andar las dichas probinçias,

El dicho capitan mo velasquez determyno de ynbiar desde el caçique que se dize MyRua en la dicha probinçia a descubrir las dichas probinçias de choco y ansi a otro dia de los dichos apostoles este testigo dixo mysa y les predico a todos los soldados y se partio e este testigo con el capitan po de moriones y con quarenta y cinco soldados a desubrir las dichas probinçias del choco y domingo despues de todos santos llego este testigo con el dicho capitan y soldados a las probinçias del choco y a los poblazones de los caçi ques Etaquisero y buricha y bara y otros caçiques Donde primero estavan dieron en un pueblo que se dize guaya y alli se çercaron ocho casas que estan en barbacoas y se ojeron y tomaron a la ora que amanecia ciento y treynta y tantas personas chicas y grandes y alli se detubo el dicho capitan este testigo y los soldádos treze dias para los sacar de paz y ellos no quysieron benyr a la paz antes binyeron de mano armado mucha cantidad de yn dios pelearon allí con los españoles los quales de dia y de noche estuvieron en vela sin durmyr y en grandisimo Riezgo.

Y al fin consultado entre todos los soldados determyno el dicho capitan $\mathrm{p}^{\circ}$ de moriones atento a los muchos yndios que en el contorno avia de se bol ver atento a que eran pocos los españoles y ansi salieron un jueves por la mañana al amaneçer con los dichos yndios e yndias naturales del choco y luego sabado siguiente estaron en las probinçias de los toOtumas huyendo en la qual enpresa se tomo cantidad de pesos de oro fino e joyas de los dichos naturales.

"El capitan $\mathrm{m}^{\mathrm{o}}$ velasquez determyno de situar y fixar el pueblo en las probinçias de los totumas En la poblazon de un caçique que se dize YaRa ma y aili le binyeron hasta treynta y quatro caçiques de las dichas probyn çias de los toOtumas y dieron la paz y sujeçion y serbidumbre al dicho capitan $\mathrm{m}^{\mathrm{O}}$ velasquez en nombre del Rey don felipe nuestro señor $\mathrm{y}$ estan en serbidumbre y hazen Rozas y casas para los españoles que alli estan...

"Aquel pueblo esta en paraje de buhio Redondo y de lo de gallo y Rolda nillo ques la parte donde los yndios totumas e Yngaraes solian salir a saltea y... despues quel dicho capitan $m^{\circ}$ velasquez entro en la dicha conquista no a sabido ny entendido que yndios dellos ayan salido $A$ hazer mal y daño a los dichos camynos...

16 En un principio, Velásquez pretendia jurisdicción también en las partes caucanas por donde ha. bia comenzado su jornada, pues en diciembre de 1573. otorgó al escribano Orellania, tanto una parcela en las cercanías de Toro chocoana como una caballería de tierra "en las sabanas desca ciude parcela en redondo" (MS VII: f. 173v). El bohio redondo, que marcabi el limite entre los distritos de li A bohio

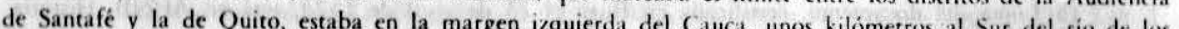
Chancos.

Este testigo a visto el apuntamyento de los yndios quel dicho capitan $\mathrm{m}^{\circ}$ velasquez en nombre del dicho señor gobernador hizo de la dichas probin- 
çias y que en ellos Repartio casi quinze mill yndios yngaraes y toOtumas y guarras, chancos. y quel dicho señor gobernador lo confirmo y dio por bueno y a dado çedulas de encomyenda de todas las dichas probinçias..

'lo quel dicho capitan po de moriones supo juntamente con este testigo de las lenguas y de los yndios e yndias que tomaron de las probinçias del choco que la tierRa de sola la lengua del choco es mas de çinquenta leguas pobla das sin hazer ynteR ucion alguna es todo poblado de poblacion trabada $y$ entre otros caçiques que ay tiene este testigo por memoria y cuenta ciento y treynta y seys Caçiques y señores que sujetan y tienen gente y que en la probinçia del choco entre otras probinçias se dibiden cinco probinçias todas de una lengua que son la primera de mamananbira donde entro el capitan Juanes de cavala y la probincia de tabira que esta a las espaldas de anzerJuanes de savalo y la probiji que ba Rodeando los chancos, toOtumas $E$ ynma, y la probinçia de termiji que ba Rodeando los chancos, toOtumas E yngaraes, y la probincia de Ysaza que esta en medio de toda la tierRa de choco y la probinçia de guaya ques donde este testigo con los demas estaron.

"Yten dize este testigo que a la otra banda del Rio del darien E azia Cabo de corRientes y panama y nombre de dios se tuvo por notiçia çierta que estaba grandisimo numero de yndios enemygos de los chocoes entre los quales estava la probincia del guaxi $y$ la probincia obuesuna. quia ques la probinçia de los yndios chiquytos y cebana que los chocoes llaman mundabida los quales dizen ser sin numero $\mathrm{Y}$ abaxo esta la probinçia de peRena donde dizen ser cosa averiguada estar la casa del diablo que los españoles llaman el dabaybe y luego la probinçia de peaberna y luego abaxo la probinçia de yndias flecheras que llaman caçiguayas que son sin ombres sino mugeres solas". (MS II: f. 75v-80).

La cronología de la jornada de 1573, descrita por Medrano, se fija santoral y calendario perpetuo en mano, así: Junio 3 , miércoles, fundación formal de Nuestra Señora de Consolación de Toro en el lugar del río Chancos, jurisdicción de Cartago; Junio 30, mártes, salida de este sitio, camino para el Chocó; Julio 19 (domingo antes de la fiesta de la Magdalena), llegada a las provincias yngaraes; Agosto 4, mártes, paso al territorio de los Tootumas, colindante con el de los Yngará. Aquí - lo dice otro documento (MS III: 449) - Velásquez puso su real en "la loma de Taparo", desde donde se podía divisar las casas y pueblos del río de los yngares. Octubre 29, juéves (el día siguiente al de SS. Simón y Judas), salida de Moriones, Medrano y compañía; domingo, 1 de noviembre, llegada de és tos a las provincias chocoes. La fecha más probable por el regreso de la entrada es el 21 de noviembre, aunque puede haber sido el 28 de éste mes.

Días después -el 6 de diciembre-se protocolizó el traslado de la ciudad de Nuestra Señora de Consolación de Toro a la comarca altochocoana de los indios Tootumas. El plano respectivo, en que Velásquez señaló la distribución de solares entre los pobladores, puede verse en nuestra Lámi na 4.

El lugar escogido para edificar la ciudad no era, como lo creyó el padre Medrano, un paraje de la provincia de Yarrama, sino un rincón de las abruptas estribaciones orientales del monte hoy llamado Cerro Torrá, a corta distancia de la cresta divisoria entre las hoyas del Cauca y del San
Juan y a unos kilómetros del río de Cara (el Río Hábita actual), "El río de la ciudad" era el afluente del Hábita que todavía lleva el nombre de Toro Viejo, por el cual iba el camino "para Sara y para los yngaraes". (MS VI: 173v). Mejor que del gigantesco "Toro primero/segundo asiento" del mapa de Salazar, se ve la ubicación exacta de la ciudad en el mapa que mandó hacer el gobernador de Popayán, Sarmiento de Sotomayor, en 1610 (AGI, Mapas y Planos: Panamá 29), cuyo nítido dibujo aclara bastante la geografía del distrito de Toro. (Véase Infra Lám. 6).

El oidor Guillén Chaparro, en su informe de 1583 sobre los pueblos españoles de la gobernación de Popayán, dice que Toro estaba situado "entre unos cerros muy altos en un llanito a manera de caldera": ubicación que n primera vista parece singularmente inadecuada para un puesto de avanzada en tierra de conquista, además de ser alejada de las ricas minas de Yarrama y Tuturrupí. Sin embargo, el sitio gozaba de muchas ventajas. Estaba en zona relativamente fresca y seca, a unos 1.500 metros de altitud, de donde por senderos de los indios se llegaba a cualquier parte de las provincias sometidas, y los alrededores estaban poblados de gente dócil que entre otras cosas, servían de parachoque contra las tribus guerreras de los contornos.

La posición.de Toro descrita por Guillén, en un llanito encerrado de altos montes, indicaría que los vestigios de población de que habla un memorial escrito en 1752 (Piedrahíta 1954: 94-97) no fuesen de la ciudad poblada por Velásquez, pues los restos se hallaban sobre una cuchilla, a un día de camino del Río Hábita. Posiblemente, eran de uno de los intentos de resucitar a Toro que se hicieron en el siglo XVII; hay también, entre las cabeceras del Hábita, una Quebrada Toro Nuevo.

Los españoles contaban 18 leguas de mal camino hasta el paso para Cartago del Río Cauca, de las cuales 16 eran intransitables para bestias de silla o de carga; 25 de malísimo camino para Cáceres, al parecer por el alto Sipí y el valle del Garrapatas, y 30 leguas de camino pésimo para los Noanamas. Sin duda las rutas eran substancialmente las mismas que aún hoy sigue el escaso tráfico de esas regiones, pero nadie las describe con precisión. Así no se puede saber por dónde anduvo Moriones y su gente en tierras de los Chocó, ya que pese a su entusiasmo, hasta el comunicativo Fray Martín mantuvo una prudente reserva acerca de los pormenores de la incursión. Posiblemente ésta no llegó muy lejos; es sugestivo el hecho de que Guaya y Bara son nombres netamente tootumas. (V. Apén, 3: Apellidos indigenas, en la parte $2 \mathrm{a}$. de estos apuntes).

Más adelante veremos el significado en términos de la cartografía moderna de algunos topónimos, hoy perdidos, que se registran en las fuentes, como también la ubicación aproximada de las tribus. Por ahora, anotamos solamente que el tantas veces mencionado río de los yngaraes parece haber sido el mismo Río Ingará de hoy, extendido el nombre hasta al menos Las Juntas y posiblemente hasta el mismo Río Tamaná actual. Nace en lo que fueron provincias yngaraes, pero en su curso inferior era habitado en ambas bandas por indios tootumas, cuyos cacicazgos se extendian por todos los lados del cerro Torrá. 
No cabe entrar aquí en la inquieta historia de Toro durante los años siguientes, cuando la irritabilidad y las emulaciones normales entre espanooles en una aislada población de frontera tuvieron clima propicio, tanto por los frecuentes cambios en el gobierno de Popayán, como por la inestabilidad del de Santafé, entregado a luchas intestinas, escándalos y bruscos trastornos de autoridad. Lo que queda en los archivos trata casi exclusivamente de pleitos y ardides, entre ellos los relacionados con la fundación, a puerta cerrada en Toro, de una ciudad imaginaria denominada Nuestra Señora del Socorro de Ocaña del Chocó ${ }^{17}$. Por cuatro años, Velásquez permaneció alejado de su creación, víctima de la mudadiza política personalista del período. Regresó después de recibir, en 1578, la confirmación regia de su nombramiento como titular de la nueva Gobernación del Chocó $^{18}$. El mismo año, condujo una expedición a las provincias del Chocó nuclear, en donde fundó, no se sabe en qué punto, la ciudad de Santiago, cuyo mando dejó a su maese de campo y teniente general, Diego Fernández de Barbosa. La empresa del Chocó no prosperó, y en 1580 encontramos a Barbosa otra vez en Buga, a donde le había precedido el Gobernador Velásquez ${ }^{19}$

Probablemente, el Gobernador había venido en 1578 con un buen número de nuevos soldados-pobladores. Sin embargo, cinco años después, no había más de cincuenta españoles residentes en Toro, de los cuales 28 eran encomenderos (Guillén 1683. Relación). En 1588-1590, evidentemente con unos nuevos reclutas, hizo sus últimos intentos de ampliar su conquista. Castellanos (Parte 3a:... Chocó: Canto 2) y Simón (Pte. 3a: Not. 7: cap. II) dan noticias de una frustrada entrada hacia el Chocó, un ensayo infortunado de bajar un río (probablemente el actual Tamaná) en balsas y canoas, y finalmente una expedición por tierra contra los Noanama del río grande, en que se perdieron cuarenta soldados y el Gobernador quedó mal herido. Involuntaria venganza de los españoles derrotados fue la viruela que comunicaron a los indios. Dos o tres meses después, el hijo mestizo de Velásquez, Melchor el mozo, fue con otra compañía para castigar a los atrevidos Noanama, y no encontró sino desolación y casas desiertas.

En enero de 1592, Melchor Velásquez presentó renuncia de la gobernación ante el presidente de la Real Audiencia, "por no poder cumplir con las cosas a que estaua obligado a causa de su mucha Vexez y pobreza". El 8 de febrero siguiente, el presidente Dr. González nombró gobernador del Chocó a Melchior de Salazar (MS I: 41; Simón 3a: 7: III).

El nuevo Gobernador, de familia hidalga toledana, era vecino de Cartago, en donde poseía minas, cuadrillas de negros y las encomiendas de Pion, Ocare y parte de Quindío. Estaba casado con Doña Ginesa, hija de

17 El divertido capítulo de la ciudad fantasma pasó en 1575 y se debatió el año siguiente ante el gobernador Mazmela y ante la misma Audiencia. Véase MS II: 103 ss; MS XIV: 1.021 ss.

18 La capitulación, otorgada por la Audiencia de Santafé el 29 de noviembre de 1576, fue confirmada por el Rey en El Escorial el 10 de octubre de 1577. El documento está publicado en Nueros Autógrafos.... número 73 .

19 MS XII: ff. 187-305, 307
Francisco de Orellana, que habia sido soldado de Gomez Hernandez en 1554 y 1557 y escribano de la expedición de Velásquez en 1573. Al momento de su nombramiento tenía unos cuarenta y dos años; estaba bien considerado, había servido en una variedad de puestos oficiales: escribano público, factor, tesorero "capitán de Putimaes", teniente en Anserma y en Cartago (MS I: 55v), y como lo anotaba el presidente González, siendo rico podía gastar lo necesario para su empresa 20 .

Posiblemente Salazar estuvo en Toro para posesionarse antes de junio En septiembre, estando en Cartago para abastecerse de "lo necesario", recibió una llamada urgente, avisándole que los indios chocoes, tatamaes y noanamas, enardecidos por la ausencia de un comandante en Toro, estaban atacando encomiendas y minas de los alrededores. El Gobernador voló a Toro, llevando "pólvora, plomo, cuerda, alpargatas, y otros pertrechos de guerra", y dió prueba de una inusitada energía en el mando. Antes de fines del mes, había despachado entradas punitivas en varias direcciones dispuesto el retiro de las "haciendas de minas" establecidas sin autorización en lugares fronteros a los Noanama y ordenado la construcción, en el Río Yarrama, de diez balsas y diez canoas para una expedición por el río grande ${ }^{21}$.

Esta expedición, que se realizó entre el 8 de marzo y el 24 de mayo de 1593, exploró por primera vez el Río San Juan desde la boca del SipíGarrapatas hasta más allá de la cabeza de marea. Descubrió el Río Calima - el "río de los yacos" de entonces- remontándolo por unas millas llevada por el flujo marino; tuvo encuentros con los indómitos Noanama; localizo unas minas explotadas por los indios, y regresó felizmente con un buen botín de oro, maíz seco y canoas. Simón, quien pudo valerse de conversa ciones con algunos protagonistas como de informes escritos hoy perdidos, da una excelente reseña de la entrada (Parte 3a: 7: III, IV), y con ella unas noticias sobre la situación que en el mismo tiempo se desarrollaba en Toro, la que preludiaba la disolución de la gobernación del Chocó.

En efecto, la fatal propensidad de los españoles para dividirse apenas ven resueltos sus más apremiantes problemas, no tardó en manifestarse entre los vecinos, algunos de los cuales, naturalmente reacios a la disciplina y acostumbrados al mando flojo de Velásquez, ya querían deshacerse del nuevo gobernador. Mientras la expedición naval iba por el Río San Juan, un prófugo de la cárcel municipal estaba en Santafé como procura-

20 Flórez de Ocáriz (Libro Primero: Vol. III) pone a Salazar en el "Catálogo de sugetos naturales del Nuevo Reyno de Granada, y sus Prouincias, con oficios, y puestos preeminentes e insignes en nawno de Granada, y sus Prouincias, con oficios, y puestos preeminentes e insignes e

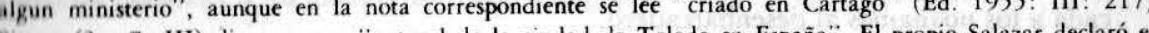
Simon (3a: 7: 1II) dice que era "natural de la ciudad de Toledo en España. El propio Salazar declaró en 1608, que era vecino de Cartago desde hacia 37 anos, eso es, desde 1571 (HDC. Núm. IX). Según Oca niz, Melchior de Salazar era hijo legitimo de Baptista de la Serna Baños y de Isabel de Salazar, toledanos; nació en 1548, y se casó en 1561: fecha ésta que debe de ser un lapso, tal vez por 1571. En 1574, estaba casado y con los suegros a cargo: peso no leve, pues Orellana afirmó ser viejo, enfermo, pobre y padre de muchas hijas (MS I: 9v, 26v). Los puestos públicos que tuvo Salazar se precisan en un "titulo" que fue entregado a la Audiencia (MS I: $55 \mathrm{v}$ ).

21 MS I: 44: Carta petición de los vecinos de Toro, 30 de septiembre de 1592 Cf Simon 3 a IV 
dor de los disidentes, pidiendo la supresión de la gobernación del Chocó y la anexión de Toro y su jurisdicción a la gobernación de Popayán (MS I: 52). Contra esta iniciativa los partidarios de Salazar se oponían en una serie de cartas y memoriales. Una de éstas comunicaciones, que se conserva inédito en el Archivo de Indias (MS I: 52v-55) merece ser conocida en sus aportes principales. Compuesta en forma de consulta, está firmada por el capitán García, el padre Solana y otros prominentes de Toro, el día 16 de julio de 1593. Dice así:

"Esta prou[in]cia de presente no tiene mas de dos çiudades que son esta de toro y la çiudad de caçeres donde entre vezinos y auitantes no ay mas de cien españoles Poco mas y Pocos naturales de $\mathrm{Paz}$ que seran como mill yndios casados... Estas dos çiudades estan en frontera y Rodeadas de los yndios de guerra chocoes, noanamas, yacos, y copomaes que continuamente las persiguen, $y$ rroban, $y$ an muerto, y cada dia matan muchos españoles y naturales y rrovado grandisima suma de haziendas y Hecho ynumerables daños... Se vio el año Pasado en esta Prouinçia que en tres meses questubo esta tierra sin gouernador luego suçedieron los muertes del capt ${ }^{t}$. Luis Franco y otros dos españoles e Yndios de Paz, que los mataron los Yndios de guerra chocoes por entrarse la tierra adentro ynconsideradamente a sacar El propio año, el cap t' diego encomendero desta çiudad, poblo una estançia en la rriuera del Río de yarrama, tierras que son frontera de los noanamas yndios de guerra y donde desembarcan y vienen a rrobar la tierra de las minas de esta çiudad; y assi le mataron alli los yndios de guerra noanamas nueve yndios y le hirieron otros quatro.

"Quel gouernador de la Prouinçia de Popayan Pueda gouernar esta tierra por su persona, niego Poderlo hazer... los casos de la guerra son ynopinados, Presçisos, Puntuales y momentaneos y no admiten dilación ni termino. mal podrá El que Esta cincuenta dias de camino de yda y buelta, rremediar ni preuenir la causa que Pide el rremedio dentro de veynte y quatro oras...

"[Salazar] entro en esta ciudad cargado de polvera, plomo, cuerda y alpargates y otras municiones de guerra, y despacho luego al cap. ${ }^{t}$ Simon Sanchez a las provincias del choco con doze soldados auiados a su costa que fue de mucho efeto... al capt. garcia guerrero... le mando Juntar veynte soldados y que defendiese las minas de río negro y yarrama mandandole que particularmente despoblase la rrancheria de santa catalina del capt. diego de paredes y las demas que estauan en manifiesto peligro...

"Enbio al cap. ${ }^{\mathrm{t}}$ xpoual garcia montaño que despoblase las rrancherias de minas de Tuturrupi que estauan en manifesto peligro y las poblase en sitio seguro.

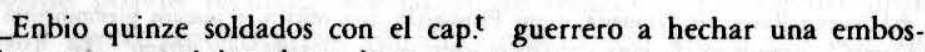
cada a los noanamas al desenbarcadero..

Alçose El rrepartimiento de yndios del capt yncapie y huyose al choco y enbio luego a Jorge hernandez por caudillo con ocho españoles [que fue] de grandisimo efeto porque Alcancaron los dichos yndios Alçados y los boluieron a su tierra.

"Hordeno que se labrasen diez canoas en el rrio de Yarrama y se hizieron diez balsas como se hizieron contra la opinion de muchos que lo dificultaron
Proveyo por cap! y caudillo al cap! cristoual garcia montaño para que fuese $A$ las prouinçias de los noanamas y con el fueron El benefiçiado xpoual de Solana y treynta y tanto soldados, todos los quales se embarcaron Por el Rio de tamana abajo animosamente por camino no bisto ni pisado otra bez de Españoles y corriendo Por el dicho rrio abajo toparon tres ca noas de yndios pequeñas, que venian delante Por çentinelas y espias de otras doze canoas grandes llenas de yndios de guerra, y otras seis que venian de tras que trayan mas de dozientos yndios de Pelea y como despues se supo de los yndios noanamas cauptibos que se tomaron, venian a destruyr y Ro. bar las dichas minas de yarrama..
be los yon

Aunque pequeña en numero Esta compañia siendo grande en valor entraron en las propias tierras y casas de los noanamas, y con auer muchos yndios quemaron y destruyeron mas de mill anegas de mayz. quemaron mas de veynte casas, tomaronles treynta y siete canoas grandes y seis yndios e yndias. y Triunfando desto sin Perder español aunque con siete heridos de nueve guacabaras que les dieron. Por el propio Rio arriba boluieron a desembarcar en yarrama

"Estos yndios declaran que va toda la tierra Poblada sobre la mar del Sur que hay quatro Provinçias de grandisima Suma de naturales y gente rrica de oro y perlas. Y una Prouincia de gente bestida en donde se pueden poblar quatro pueblos españoles y mas - que. con esta sera una Prouncia muy rrica y dilatada y se podra poblar y dilatar mas, Pues tiene mas de ciento y cincuenta Leguas de Longitud donde no Puede dejar de auer buenas y rricas tierras que poblar...

En lo que $\mathrm{Al}$ gouernador toca melchior de salazar en su persona ay cris tiandad, calidad, cantidad, Retitud y Prudençia para gouernar.

Este damos y es nuestro Parescer salbo el mejor de V.A. a quien dios nuestro señor guarde. de toro y de jullio 16 de 1593. años

Xpoual garçia, Rodrigo de rrojas. garcia guerrero. de Xerez. diego martinez. Pedro de herrera. el lic. do Juan alonso yncapie yo pedro de caruajal escrivano mayor de gouernacion Publico y del cauildo de esta çiudad de Toro

No es éste un documento imparcial y desinteresado; las fuentes in mediatas de la historia pocas veces lo son. Por ejemplo, las cotidianas ma sacres por parte de las bravas tribus colindantes, es pura hipérbole; los indios sometidos y en especial los pobres Yngará, eran hostigados, pero hasta donde se sabe, Toro nunca fue atacado, y aparte de la entrada de guerra de Velásquez en 1590 (cuando sólo la mitad de las pérdidas se debían a la acción enemiga), no hay noticia de más de tres españoles víctimas de las armas indígenas. Sea como fuera, las representaciones en pro de Salazar y su gobernación no lograron el efecto anhelado.

\section{Fin de la gobernación del Chocó}

Se ha discutido mucho la fecha en que se acabó el gobierno del Chocó y que Toro, nuevamente agregado al de Popayán, fue trasladado de las faldas del Torrá a la margen del Cauca. Simón, en un curioso lapso, dice que el traslado fue ordenado por el Gobernador de Popayán en 1587, 
y un autor moderno acoge la fecha añadiendo que el gobernador en cuestión era Maxmela (quien gobernó en 1576); Arroyo dice que el gobernador de Popayán que dispuso el traslado fue Ordoñez de Lara (diciembre 1589 enero 1591). Diógenes Piedrahita, en vista de las pruebas documentales de que el gobierno del Chocó existía, independientemente de posibles ingerencias del de Popayán, hasta bastante después de las fechas indicadas, cre que la mudanza de Toro al sitio en que actualmente está, debe haberse efectuado después de 1600 (1954: p. 62). Los documentos del inédito "ex pediente Salazar" - nuestro MS I- en el Archivo de Indias, despejan esas incertidumbres.

La supresión de la gobernación del Chocó y la incorporación de Toro y Cáceres en la de Popayán, fue decretada por el Presidente González al principio del año 1595 , después de más de un año de representaciones contradictorias, acusas y contra-acusas, peticiones, memoriales y propuestas diversas por parte de los españoles de Toro (MS I: f. 52-59v; Simón, Pte. 3: Not. 7: c. IV). Entonces el gobernador de Popayán, a la sazón Don Diego de Noguera Valenzuela, proveyó o "permitió" el traslado de Toro mientras Cáceres dejó de existir. Sobre estos hechos Melchior de Salazar escribió, el 15 de abril de 1596 (MS I: 6v-7):

"Despues de que se me quitó la Gobernación del choco Por auer el Gouernador de Popayan permitido que se despoblase la çiudad de caçeres de todo punto y que la çiudad de Toro se mudase al Rio de las garrapatas que por ser El sitio enfermo y contrario A la salud humana se an muerto muchos naturales y esPañoles por la cual la despoblaron de aqui y la pasaron a las Riveras del Rio de cauca que estas mudanças en un año an sido causa de su destruycion".

La estadía en el valle del Garrapatas debe haber sido casi tan breve como él en el Río Chancos en 1573. Es interesante, sin embargo, saber que la situación actual de Toro representa el tercer traslado de la ciudad.

El memorial arriba citado, pertenece a la campaña emprendida por Salazar para recobrar la gobernación perdida, y recobrarla con creces, pues "si se a de servir al rey nro. señor en su Reformacion y ampliacion a de ser con las mas largas mercedes". Las mercedes pretendidas eran largas de verdad: "que se me de la Gobernación por tres vidas, una mia y dos de mis hijos y succesores...", “que no se nos pueda tomar Resi dençia ni visita hasta que ayan passado veynte años..." que no podría ser removido por incumplimiento suyo sino solo multado, y que a mas del vasto territorio entre Buenaventura y Acla en el Istmo, "desde luego se me yncluyen en la Jurisdiçion del dicho Gouierno las ciudades de Anzerma y Cartago que oy son del gouiemo de Popayan para q. se encorporen $\mathrm{E}$ yncluyen la dicha Gouernaçion con sus términos y Juricicion $[\mathrm{vic}]$....". El, por su parte, pondría 50 esclavos negros para las minas y 200 vacas, haría cultivar 8 hanegas de maíz, reedificará a Toro y Cáceres y haria un puerto de mar "en el Rio de tamana por mi descubierto" (MS I: $3 \mathrm{v}$ ). No es sorprendente que la propuesta no tuviera acogida.

Los dos documentos más importantes del inédito expediente Salazar, el mapa etnográfico y la relación a éste anexa, tenían por objeto poner en relievo tanto el potencial del Chocó como la calidad de Don Melchior, y llevan la misma fecha del memorial sobre la recreación de la gobernación chocoana. Antes de presentarlos, sin embargo, será preciso decir algo de Cáceres, la segunda población española del Alto Chocó, de la cual ya queda mención en los escritos citadas en páginas anteriores.

\section{Nuestra Señora de la Concepción de Cáceres}

En el lapso de menos de tres años, se fundaron dos Cáceres, sucesivamente, en partes amenas de la Cordillera en lo que hoy es el municipio vallecaucano de Bolívar. La primera, a que se dio título de villa, fue abandonada antes de que se concretara, en 1573; la segunda, denominada la ciudad de Nuestra Señora de la Concepción de Cáceres, duró - no se sabe bien por qué- casi cuatro lustros. Ambas fueron fundadas por el capitán Francisco Redondo ${ }^{22}$ en virtud de comisiones otorgadas por don Gerónimo de Silva para la pacificación y población de las provincias de los Chanco y los Chocó: el mismo cometido confiado a Melchor Velásquez en octubre de 1573 .

Del primer ensayo de Redondo se dijo:

"Entró a las dichas Provincias chancos y chilomas y sin conquistarlas se salio dellas y Poblo un Pueblo que se llamo la Villa de caçeres, la qual despues de Poblada los Vezinos Justicia y Regimiento que fueron nombra. dos la dexaron y desampararon de su Boluntad de su suerte que jamas la an Buelto a Reedificar". (MS IV : 8-8v).

Según otra opinión, el despoblamiento se debía a una disposición del robierno: porque necesitaba los soldados para la guerra con los Páez, y porque el sitio escogido para la Villa no correspondía a las instrucciones dadas al respecto, ya que no estaba en tierra chocoana sino en las partes aledañas al curso alto del río todavía llamado "de Cáceres". Es de suponer que esto sucedió antes de que se suscribiera el asiento con Melchor Velásquez; lo difícil de comprender es por qué Silva, en 1574, dio otra igual comisión a Redondo, al tiempo que reconfirmaba aquella otorgada a Velásquez (MS IV: 8v; MS II: 220; MS IX: 186). Y esa curiosa duplicación no fue solamente por idiosincrasia de un mandatario ya dimitente. Persistió, con mayores enredos, en los años siguientes, hasta en los Acuerdos de la Real Audiencia.

22 Francisco Redondo, hijo del conquistador y rico encomendero de Cali, Antonio Redondo, recilió su segunda comisión del dimisionario gobernador Silva el 1 de mayo de 1574 (MS II: 220). El cafuildo de Cali discutió el asunto el 30 de septiembre siguiente: había quien defendió los derechos de Ve lasquez y quienes propusieron otros capitanes por jefes a co-jefes de la jornada. En la votación ganó la hisque y yaces proptsieron otros capitanes por jefes o co-jefes de la jornada. En la votación, ganó 1 Huse raticí la comisión el 28 de febrero de 1575 (MS II: 223) y otro tanto hizo su sucesor, el interi-

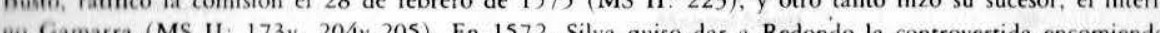
no Gamarra (MS de los Gorrones (AGI, Audiencia de Quito: Leg. 16), pero la concesión no fue aprobada: en 1576, el procurador de Caceres dijo que los Gorrones estaban en la Coronal Real (MS IV: f. 8). En 1579 trancisco Redondo era alcalde ordinary de Cali (MS VIII: $170 \mathrm{v}$ 24 
Redondo debe de haber salido para su segunda expedición en agosto de 1575, ya que a fines del enero siguiente dijo que eran seis meses que iba en el castigo de los Chanco (MS II: 167, 205). Por lo que dicen las fuentes, la fundación de Nuestra Señora de la Concepción de Cáceres habrá sido solemnizada el 8 de diciembre de aquel año. El lugar era la parte occidental de la ya aludida depresión de la Cordillera hoy denominada La Llanada, en el mero borde del territorio por someter. En cuanto a la jurisdicción de la ciudad, nada se dice de preciso; hay mención del valle del río de la ciudad que va hacia Poniente, que debe ser el del río de La Llanada con el Sanquininí inferior, y que parece haberse llamado Nainza, y de un segundo valle nombrado Bebomo. También se refiere el valle y provincia de Chanquinina, a la izquierda del que desde la ciudad bajaba hacia occidente. (MS IV: 13, 22v, 23v).

Fundada la ciudad, apuntado el repartimiento de los indios entre los pobladores y nombrado por teniente a su hermano Juan, Redondo se fue para Cartago y Santa Fe, "a pedir la jornada del Chocó". Como había hecho un repartimiento también en la primera entrada, surgió inmediatamente una controversia entre encomenderos antiguos y nuevos, que fue llevada hasta la Real Audiencia. No tenemos el apuntamiento original, pero sí el que se incorporó en la decisión a que llegó la Audiencia en Julio de 1577, y la forma revisada de ésta fechada un mes más tarde, por la cual se distribuyó a 1.720 indios entre 25 vecinos de Cáceres (MS IV: $22 v-27)$. El repartimiento está resumido en nuestra Tabla 1, y de ello se ve que los españoles cacereños conocían poco la región que pretendían explotar. Al parecer, nunca lograron hacer realmente efectivas sus encomiendas, pues en 1582, Fray Gerónimo de Escobar dijo que los indios de distrito de Cáceres, que se calculaban en unos 3.000 (varones), “aún no estan conquistador ni ay dellos veynte que ayan rrescibido el santo bautizo". Al decir de Escobar, los vecinos no tenían otro recurso que el trato de los naturales: "lo que por la presente fazen, entran alla e sacan de los yndios e traenlos a otros pueblos e sirvanse dellos en sus granxerias". E Dr. Guillén Chaparro, sin embargo, se refirió un año más tarde a Cáceres en términos mucho menos sombrios, y es cierto que en 1583 la "ciudad" tenía residentes estables (inclusive unos venidos de Toro), una organización municipal con notaría y cura párroco y un cierto desarrollo agropecuario.
REPARTIMIENTO DE LOS INDIOS DE LA CIUDAD DE NUESTRA SEÑORA DE LA CONCEPCION DE CACERES, ELABORADO Y REVISADO POR LA REAL AUDIENCIA DE SANTAFE EN 1577 .

\section{2. versión, Jullo 23 de 1577}

Versión final, agosto 9 de 1577

. "En el primer valle como van entrando de la dicha ciudad hasta donde se pone el sol yendo el rrio abajo a mano izquierda"

Juan Redondo

Luis Ponce de Llanos

Juan Martin Blasco

Juan Serrano

Pedro Vanegas

Diego Castillo

Bartolomé Urgile

Juan Ramirez

$\begin{array}{r}100 \\ 80 \\ 100 \\ 80 \\ 80 \\ 80 \\ 80 \\ 80 \\ 80 \\ \hline\end{array}$

Francisco Redondo

Luis Ponce

Miguel Ballesteros

Juan Serrano

Pedro Vanegas

Diego Castillo

Capto Une

The decions

. "En el rrio abajo del dicho pueblo de caceres a mano derecha por las poblacones del"

Capitán Burgüeño

Francisco de Aguirre

Pedro de Valderrama

Diego de Llanos

Bartolomé Ximénez (a)

Diego Redondo

$\begin{array}{r}80 \\ 80 \\ 60 \\ 60 \\ 80 \\ 50 \\ \hline 410\end{array}$

Capitán Burgüeño Francisco de Aguirre
Francisco de Ortega(b) Diego de Llanos Miguel Hernández Gabilán Diego Redondo

(con el cacique que posee)

b) Hijo de Juan de Ortega.

a) Excluido luego por mal encomendero de Toro

3. "En el segundo valle de bebomo ques distinto $e$ apartado de 3. "En el segundo valle de bebomo ques distinto eap
el valle primero el rrio arriba a mano derecha"

Ambrosio de Miranda $\quad 80$ (con el cacique Massi)

\section{Rodrigo de Bendala(c)}

Francisco de Fuenlabrad Gabriel Sánchez

$\begin{array}{r}80 \\ 60 \\ 50 \\ 50 \\ \hline 240\end{array}$

Ambrosio de Miranda

Gaspar Osorio

Francisco de Fuenlabrada

Gabriel Sáncher

\begin{tabular}{ll}
60 & Francisco de Fue \\
50 & Gabriel Sánchez \\
\hline
\end{tabular}

c) Hizo dejación

4. "En el mismo valle de bebomo el rrio abajo"

Francisco Redondo

Francisco de Ardila

Juan de Ancueta

Francisco Hurtado

$\begin{array}{r}90 \\ 80 \\ 70 \\ 80 \\ 70 \\ \hline 390\end{array}$

Francisco Redond

rancisco de Ardila (con el cacique que posee) Juan de Ancueta Melchor Estéban

Pero Telles de las Peñas "se le confirma su apuntamiento de 100 yndios"

$\begin{array}{ll} & \text { Pero Telles de las Peñas } \\ & \text { "se le confirma su } \\ \text { apuntamiento de } 100 \text { yndios" }\end{array}$

5. "En los valles que llaman de chilomas y otros alli comarcanos que aun no estan de paz"... "En los chilomas y coponamaes" Alonso López

60 Alonso López
Manuel López Miguel Hernández Gabilá Capn. Leonel de Ovalle
80

50

$\begin{array}{r}70 \\ 50 \\ \hline 330\end{array}$

100

$(1)$

60
30
30 
Que sepamos, Francisco Redondo nunca intentó realizar la comisión que le confirió la Audiencia en 1576, probablemente porque antes de poder organizar la empresa, tuvo noticia de que el rey Felipe había aprobado a Velásquez como gobernador del Chocó. No volvemos a encontrar su nombre en conexión con la vida y muerte de Nuestra Señora de la Concepción de Cáceres.

\section{El mapa etnográfico del Chocó y la "Descripçion de la tierra".}

El mapa que dibujó Melchior de Salazar en 1596, en el cual la América hispana no es sino un marco para el Chocó y especialmente para el Chocó meridional, se reproduce en las Láminas 1 y 2 . La Lámina 2 presenta en forma más amplia, la parte correspondiente al Alto Chocó, la que a su vez se traduce en nuestro mapa moderno (Lámina 3). Para mayor claridad, anotamos algunos equivalentes actuales de los topónimos em-
pleados por Salazar.
Salazar
R.D. Tamana
R. Caçarbado
R. Darien
R.D. Perre
puerto de buenaventura
R. Yarrama
R. Tuturrupi

$$
\begin{aligned}
& =\text { Río San Juan } \\
& =\text { Río Baudó } \\
& =\text { Río Atrato } \\
& =\text { Río Dagua inferior } \\
& =\text { Rio Anchicayá }(23) \\
& =\text { Río Cajón } \\
& =\text { Río Sipi }
\end{aligned}
$$$$
\text { Nombre moderno }
$$

La Descripçion de la tierra, complemento del mapa, es la que sigue:

Planta de la Tierra

"Lo queen declaraçion deste Mapa puedo desçir es lo primero. que yo no soy Cosmographo y asi se a de rrescibir por obra de hombre. que yo no a puro trauajo de yngenio y ynquisicion de nabegantes y bista otros espanoles por tierra y rrelacion de yndios ecolegido lo pintura pintura. Solo para demostrar la demarcaçion de las prouinçias del Choco de que yo fue gouernador y me estaba cometida el descubrimiento paçificacion y poblaçion de ella con 150 leguas de longitud corriendo açificaçion de el puerto de la buenabentura y 100 leguas de latitud desde la cordilles. de rroldanillo pueblo de yndios de la rreal corona Al Ocidente El Puerto de la buena bentura esta en tres grados y dos tercios
de la Equinoçial a la parte del norte y corriendo de aqui a la çiudad de Panama por la costa Maritima para donde se endereça la dicha demarcaçion de longitud ay los cabos y Puertos siguientes

Desde la boca deste Puerto de la buena bentura a el Rio de los Noanamas abra 19 Leguas. Ay vnas Provinçias de yndios llamados Perres, guerbaros, chilomas, cagaçimbes, burgalandetes yacos bistos por españoles $q u$, avnque no son muchos son bastantes juntos con los Noanamas para poblarse en ellos vna çiudad

La boca y entrada del Rio de Tamana en la mar del sur esta en 28 yamarra que corre por medio de las minas de la çiudad de Toro y entra en este poco mas abajo de las dichas minas.

La rribera deste Rio de vna banda y de otra es abitado y poblado de vnos yndios llamados Noanamas. es gente de buena dispusiçion y de buenos rros tros Asi hombres como mugeres. traen Las mas oradadas las bentanas de las nariçes y en ellas vnas perillas de oro fino, tienen oradada la ternilla de la nariz y de ella colgada vna argolla de oro que llaman caracuri. traen orada. do el labio ynferior con quatro agujeros y en ellos puestos vnas tiras de oro de seis o siete dedos en largo a manera de barbas traen oradadas las orejas y en ellas vnos aretes de oro gordos como un cañon de ganço. traen unas patenas en los pechos Rodeadas de muchas conchas Maritimas de las que crian las perlas. es gente baliente. pelean con dardos que tiran fechos de palma. la tierra es sana. fertil y abundante de mays y frutas y palmas puercos de monte çaynos y mucho pescado y cangrejos. ycoteas. sal. allaronse en este Rio muchos pezes espada. bieronse abiertas en esta tierra muchas minas de oro que labran los naturales. Preguntando yo a vn yndio Noanama que en el biaje dicho se tomo llamado en su lengua Aricum que yo tengo en mi poder con las dichas ynsignias de oro/donde lo sacaban y como se llamaba donde lo labraban dijo que de los arroyos de su tierra y que lo quemaban en el fuego y que le daban golpes con piedras y que se llama en su tierra pino. preguntado que de donde trayan las dichas conchas de perlas dijo que del agua grande salada. preguntando como lo sacan dijo que se atan cabuya de palo ques soga con vna piedra en el agua. quel no sabe desçir se somorgujan o se çabullen. preguntando si tiene perlas y mostradas. dijo tener muchas y que se llaman soromas. Dize este yndio que los dias pasados llego a este Rio vna casa grande que se entiendo, nabio. Y que del salieron mucha gente y que salieron a ellos los yndios y tomaron quatro españoles $y$ un muchacho $y$ una bieja y dos muchachas mugeres blancas $y$ rrubias que la bieja y el muchacho son muertos y que las dos moças estan acomodadas con dos yndios caçiques de que tienen hijos. Dize que enderesçando al setentrion estan las prouinçias de yndios botabiraes. y ques jente mucha. y que pelean con dardos como los Noanamas y que tienen mucho oro en los Rios. y que traen Joyas en las nariçes y orejas. Mas abajo destos dize estan las prouinçias de los yndios Eripedes junto a un Rio muy grande que se llama Caçarbado dize questos tienen mucho oro y que pelean con flechas. Junto a un Rio grande que sale a la mar

De la otra banda deste Rio dize estan mucha genta de yndios que llaman Orocubiraes y ques gente bestida. la mitad del cuerpo con mantas gordas, y tierra de çabana y questos tienen muchas perlas y se las ponen en el cuerpo que yendo este yndio con su hermano ques caçique grande de los Noanamas a pelear con estos Los a bisto. y que ban en quatro dias por la mar en sus canoas costa a costa, durmiendo en tierra/ conforme este yndio con el piloto de la mar del sur del barco de la buena bentura que me escribio que bajando para Panama el año pasado de 1593 yendo a tomar agua Allo mas de quinientos yndios en la boca deste Rio pescando, y asi se paso sin osar tomar agua

Por la banda del Norte deste gran Rio de Tamana Rio arriba entra otro Rio pequeño que dize el Noanama que se llama Pucutado en el queal [^] y que en sus rriberas abitan las Prouinçias de yndios llamados çirambiraes y ques mucha gente. y el $\operatorname{cap}^{\mathrm{n}}$ xpoval garçia que por comision mia fue a hazer este descubrimiento tubo en su poder un yndio y una yndia çirambiraes e por no tener lengua con quien le preguntar no se tomo rrelaçion clara y este yndio le engaño y se le fue diziendo que su muger quedaba 
ally que yba por dos hijos que tenia y dejando dicho a su muger que se fuese a la noche lo hizo asy y nunca mas bolbieron ni se tomaron otros

Dende la boca deste Rio que los yndios llaman caçarbado A cabo de corrientes questan en 5 grados $2 / 3$ abra 15 leguas. en este parage esta vna Prouinçia de yndios llamados Mariramas donde se tiene notiçia que entro/el adelantado Almagro con 170 españoles y poblo vn pueblo el queal le quemaron los muchos yndios que sobre el binieron con muertes de quarenta españoles. le forçaron a rretirarse a la mar abiendo quebrado un ojo al adelantado de un flechaço. Desde cabo de corrientes a puerto de piñas questa en 6 grados y $1 / 3$ abra doze leguas por este parage entro el cap ${ }^{n}$ baeça que salia de Panama con 150 hombres y los muchos yndios que dieron en el le mataron y con su muerte dejo nombre a la tierra que se dize el valle de baeça.

Endereçando desde este puerto de piñas a panama costeando se llega a la punta de carachine questa en 7 grados y $1 / 3$ y de aqui dejado la tierra se rreconosçen las yslas que se llaman de perlas que seran casy 25 donde se an sacado y sacan muchas perlas. estan en 7 grados y $2 / 3$

Luego paresçe la çiudad de panama questa en 8 grados como dicho es de la equinoçial A la banda del norte

De aqui salio el adelantado Vasco nuñez de balboa y entro en estas prouinçias y saco de rrescates y presentes mas de cien mill pesos de oro y perlas de que naçio la discordia entre el y pedrarias de avila

Por la parte de tierra esta esta prouinçia del choco, se parte y limita con la gouernaçion de popayan por una cordillera que casi las dibida, que ba corriendo por el parage donde estubo poblada caçeres e esta hoy toro. y anzerma que ba corriendo la dicha cordillera Norte Sur algo torçido en partes desde mas arriba de popayan asta la mar del Norte. desta propia cordillera a las espaldas de anzerma nasçe el dicho Rio de Tamana que entra en la mar del Sur. a la mar del Norte deste propio parage nasçe el gran Rio del darien que da su tributo a la mar del Norte. entre los nasçimientos destos dos Rios esta la prouinçia del choco oy muy despoblada porque los muchos naturales que tenia quando fue descubierta se an rretirado la tierra adentro huyendo la çercania de los españoles por tenerlos en la çiudad de anzerma y toro muy çerca. corriendo por el Rio del darien abajo ay muy publica y çierta notiçia questa la gran Riqueza del dabaybe de cuyas grandes rriquezas no se puede escribir, Lo quai los yndios dizen tiene, ni lo que los españoles creen porque paresçen fiçiones de Libros de caballerias. y no es posible sino que en tanto largueza de tierra como ay desde el puerto de la buena bentura A acla de Longitud y Latitud abra otras muchas prouinçias de yndios 9 poblandose lo descubierto cada dia se yra descubriendo y poblando. porque por un memorial que tengo fecho por el $\operatorname{cap}^{n}$ fran $^{\text {co }}$ de orellano mi suegro que salio perdido abra quarenta años por el dicho Rio del darien nabego la mayor parte del y sus contornos y dize topo muchas prouinçias de yndios pequeñas de a siete y ocho mill yndios. y como en aquel tiempo buscaban los españoles a las grandezas del Piru o nueba españa no les contentaron estas que agora tenemos Por buenas

Bien conosco que no e guardado horden en esta figura porque abiendo 23 grados y $1 / 2$ desde el tropico de cansçero a la Linea coliçita abia de encerrar toda la tierra que ay desde la Linea a Panama en La medida de tierra o Leguas que cupieran a ocho grados, contando 17 leguas por 


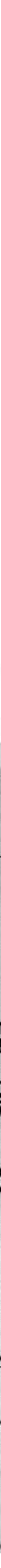




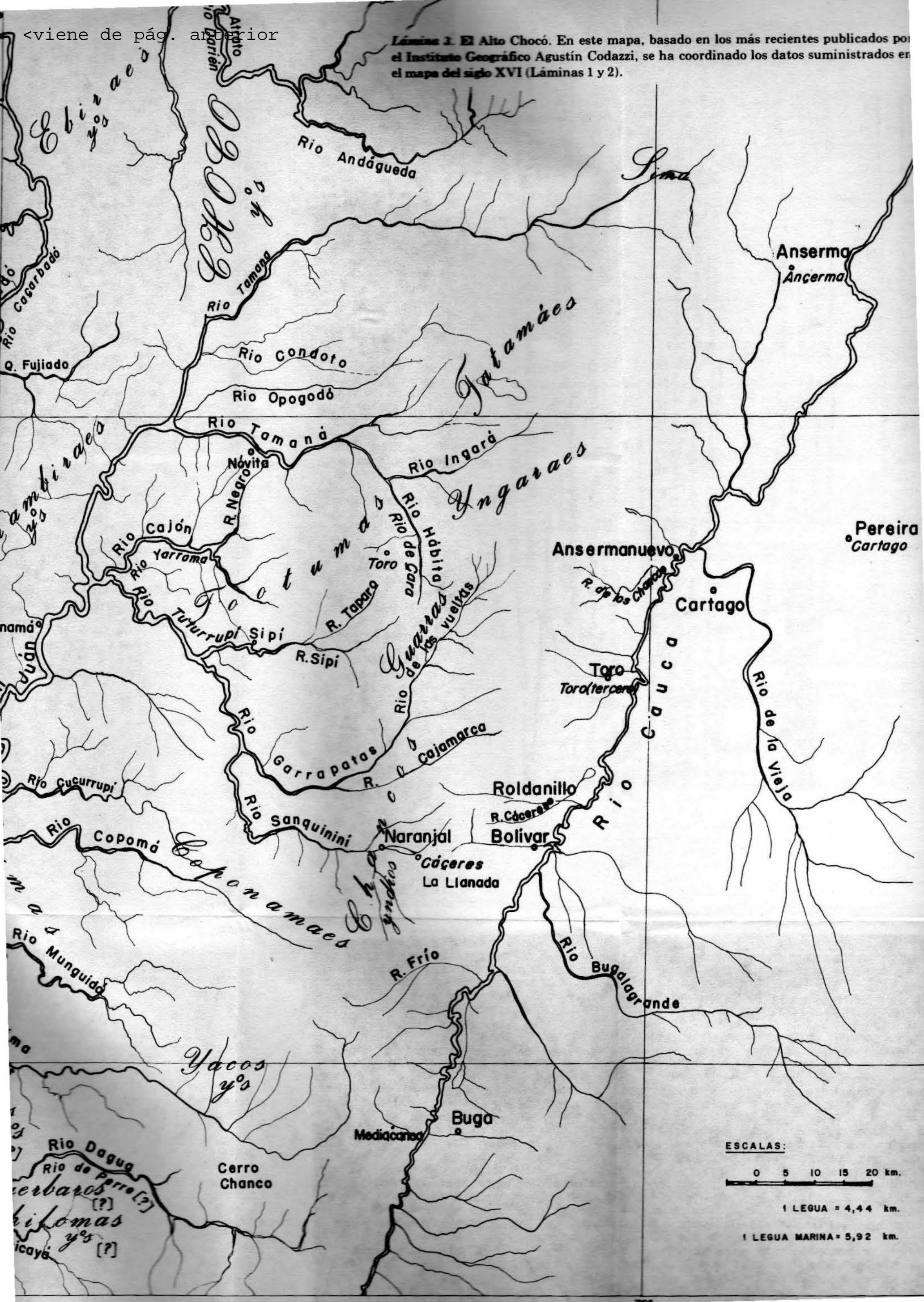




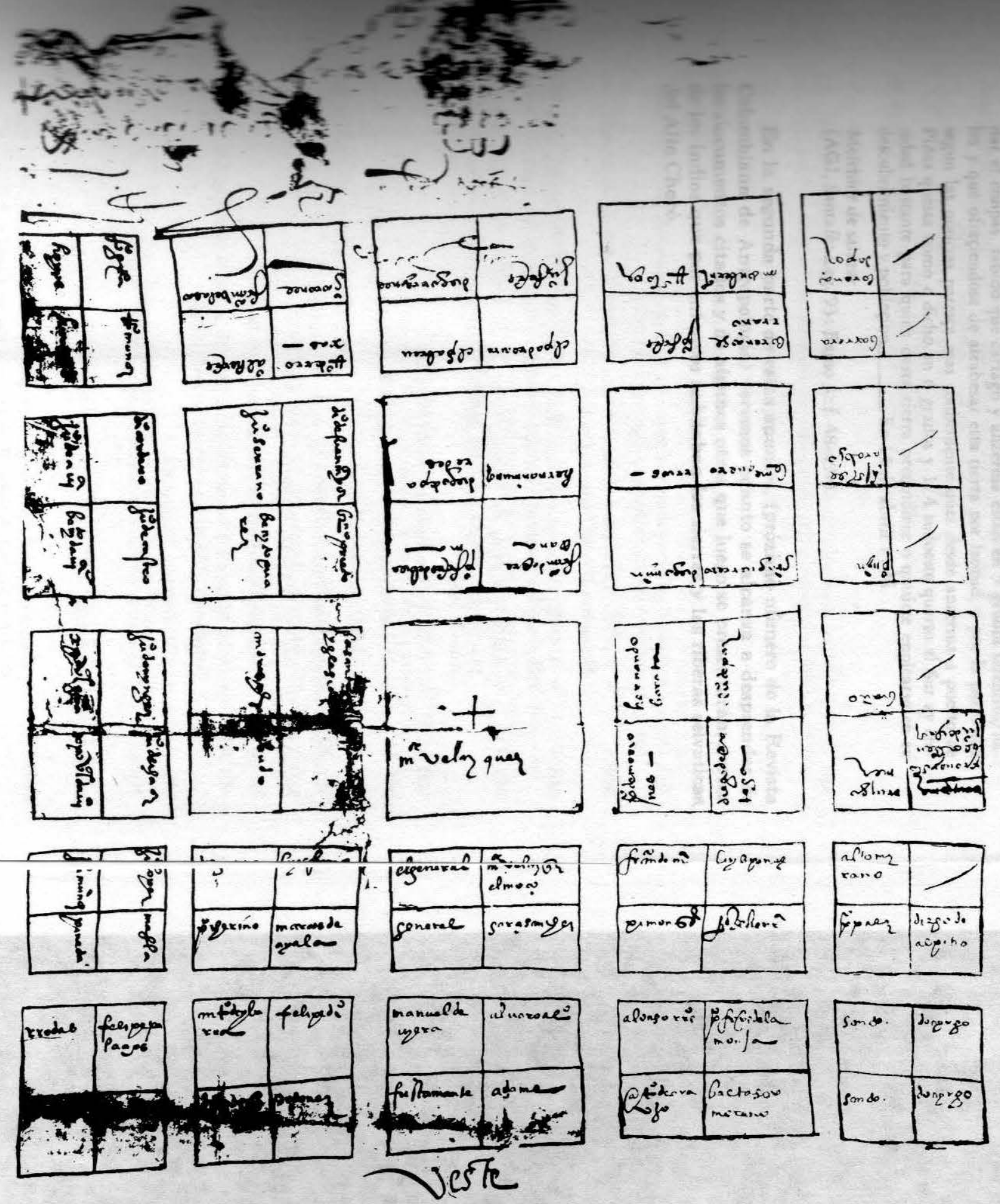

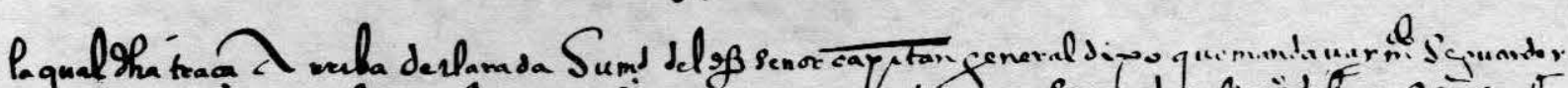

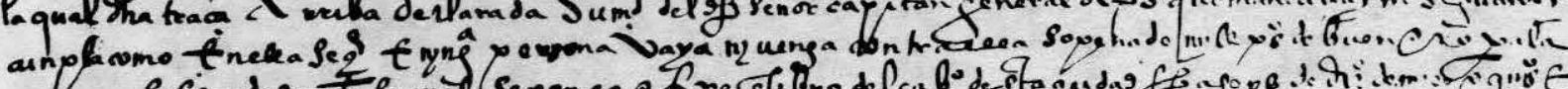

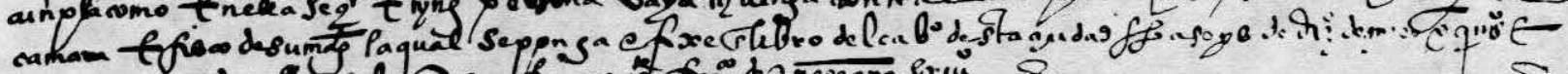

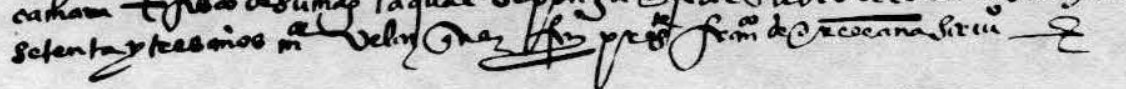

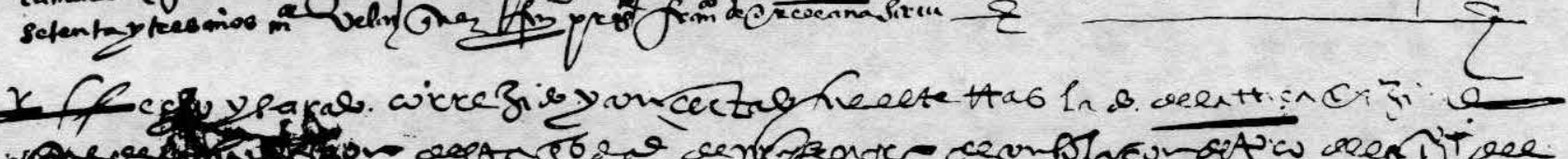

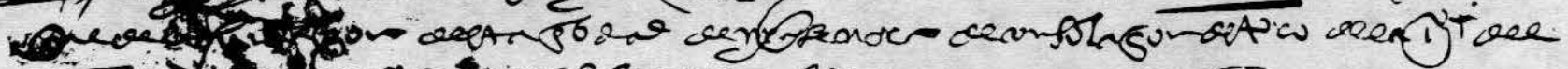

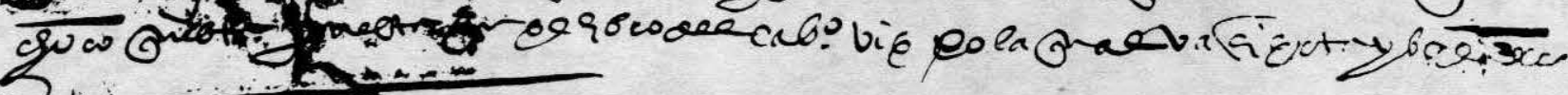

Lámina 4. Plano para la distribución de solares entre los pobladores de Toro. Diciembre 6 de 1573. (AHNB, Sección mapas: No. 486A. Archivo Histórico Nacional, Bogotá). 
grado o el compaz que este puesto partirle en 22 partes y $1 / 2$ pero como no es del proposito la puntualidad de grados sino tan solamente la manifestaçion de las prouinçias que contiene La demarcaçion desta prouinçia del choco y porque bayan con mas claridad y menos confusion. y yo no se algo del arte de pintar enderesçe a declarar Las prouinçias sin la guarda de la graduaçion questa con rretirar la Linea del tropico mas al setentrion y guardar el conpas. sabido que cartago y anzerma estan en 5 grados setentrio/nales y que ofreçiendose de atrabesar esta tierra por latitud, y por la parte que segun las notiçias paresçe mas conbeniente ques desde anzerma a puerto de Piñas questa como e dicho en 6 grados y $1 / 4$ sudoeste quarto al Sur ay claridad bastante para quien desta tierra pretendiere o quisiete enplearse en su descubrimiento y poblaçion En 15 de abrill 1596.

Melchior de salazar

(AGI, Santafé: Leg. 93: Ramo 3: f. 48-49v).

En la segunda parte de estos apuntes, (próximo número de la Revista Colombiana de Antropología) veremos cuanto se alcanza a desprender de los documentos citados y de algunos otros que luego se presentarán, acerca de los indios que por entonces habitaban las sierras y las riberas selváticas del Alto Chocó. 

quista y colonización de las antiguas posesiones españolas en Améri. ca y Oceanía. Ed. Luis Torres de Mendoza et al. 42 tomos. Madrid. 1864-1884.

Siglas

ACC

ADVG

AGI

AHNB

AHMC

ARAH

= Archivo Central del Cauca, Popayán.

= Archivo Dominicano, Fondos Vacas Galindo, Quito.

= Archivo General de Indias, Sevilla

= Archivo Histórico Nacional, Bogotá

= Archivo Histórico Municipal, Cali.

= Archivo de la Real Academia de la Historia, Madrid

MS I = AGI, Audiencia de Santafé: Legajo 93: Número 14; Ramo 3: Doc. 30 (Documentos y notas reunidos por Melchior de Salazar, 1574-1596)

MS II = AHNB, Colonia: Historia Civil: Tomo III. (Escrituras, cédulas, probanzas, cartas, etc., relativos al Chocó meridional, 1572-1578).

MS III = AHNB, Encomiendas: Tomo I: ff. 430-879. Pleito de Diego de Pare des con Juan Alonso Hincapié, por indios, $1582 \mathrm{ss.}$

MS IV = AHNB, Encomiendas: Tomo IV: ff. 5 ss. Autos en razón del apuntamiento de los indios de Cáceres, 1576 - 1577.

MS V = AHNB, Caciques e Indios: Tomo VI: f. 88 ss. Pleito de Rodrigo de Rojas con Diego Ortega por indios, 1577.

MS VI $=$ AHNB, Caciques e Indios: Tomo X: ff. 694-773. Pleito del tutor del heredero de Alonso Hernández, con Cristóbal García Montaño, 1578.

MS VII = AHNB, Tierras de Cauca: Tomo II: ff. 2-359v. Pleito por una estancia otorgada en 1573 por Melchor Velásquez al escribano Orellana. Año de 1601 .

MS VIII = AMC, Primer libro del cabildo de Cali.

MS IX = AGI, Audiencia de Quito: Legajo 16.

MS $\mathrm{X}=$ ADVG, Secular: Tomo 16 .

MS XI = ADVG, Secular: Tomo 17

MS XII = ADVG, Secular: Tomo 31 .

MS XIII = AHNB, Caciques e Indios: Tomo IV: ff. $1.021 \mathrm{ss}$.

MS XIV = AGI, Mapas y Planos: Panamá 329. Es el mapa que hizo Méchior de Salazar en 1596, antes en Aud. de Santafé 93.

MS XV = AGI, Justicia: Legajo 564

Muñoz = Colección de Juan Bautista Muñoz, ARAH, Madrid

\section{Documentos publicados}

DGHC

= Colección de documentos inéditos sobre la geografia $u$ la historia de Colombia. Ed. Antonio B. Cuervo. 4 tomos. Bogotá, 1892-1894.

DIHC

= Documentos inéditos para la historia de Colombia. Ed. Juan Friede. 10 tomos. Bogotá, Academia Colombiana de Historia. 1955-1962.

DIRDU = Colección de documentos inéditos relativos al descubrimiento, con . quista y organización de las antiguas posesiones españolas de Ultra. mar. 25 tomos. Madrid, Real Academia de la Historia.

ANDAGOYA, Pascual de

Carta al Rey, Cali, 15 de septiembre de 1540. En Trimborn 1954: pp. 179-196.

AUNCIBAY, Francisco de

Informe sobre la población indígena de la gobernación de Popayán (1592). AGI, Patronato: Leg. 240: Ramo 6; fotocopia en ACC, Colonia: Signatura 12069. En Anuario Colom. biano de Historia Social y de la Cultura: Núm. 1, 1962: pp. 197-208.

ESCOBAR, Fr. Jerónimo de

Memorial de lo que toca a la provincia de Popayán (1582). Transcripción en Muñoz, T. 24: núm. 206. En Anales de Instrucción Pública, junio-julio 1889, Bogotá; Archivo Histo. rial, febrero de 1919; Jijón y Caamaño 1936: II: Documento 6.

GUILLEN CHAPARRO, Francisco

Memoria de los pueblos de la gobernación de Popayán y coas y constelaciones que hay en ellos. Copia en Muñoz: T 24: Núm. 208. Anales de Instrucción Pública, agosto de 1889; Archivo Historial, Núm. 10, febrero de 1919.

$\mathrm{HDC}=$

Historia Documental del Chocó. Ed. Enrique Ortega Ri caurte y Ana Rueda Briceño. Bogotá, Publicaciones del Departamento de Biblioteca y Archivos Nacionales. 1954.

ROBLEDO, Jorge y Pedro Sarmiento

Relación del viaje que hizo el muy noble señor Capitán Jorge Robledo. Cali, 12 de octubre de 1540. (Muñoz, Nú meros $1.041,1.042$ ). DIRD II: pp. 267-291; DGHC II: 437-452. Jijon y Caamaño 1938: II: Documento 5.

Otras obras wawhen $10.3 \times$ Archivo Historial (Ed. Enrique Otero D'Costa). Año 1; 1919.

ARROYO, Jaime

1955
Historia de la Gobernación de Popayán. 2a. edición. 2 tomos. Bogotá

CASTELLANOS, Juan de

(1589)

Elegias de Varones ilustres de Indias. 4 tomos. Bogotá, Bi

195

blioteca de la Presidencia. 
CIEZA DE LEON, Pedro de

(1553) La crónica del Perú. Bogotá, ediciones de la revista Ximé1971 nez de Quesada.

\section{FERNANDEZ DE NAVARRETE, Martín}

1825-37 Colección de los viages y descubrimientos que hicieron por mar los españoles desde fines del siglo XV. Tomo III. Madrid. (5 tomos).

FERNANDEZ DE OVIEDO, Gonzalo

1851-55 Historia general y natural de las Indias, Islas y TierraFirme del Mar Océano. 4 tomos. Madrid, Real Academia de la Historia.

FERNANDEZ DE PIEDRAHITA, Lucas

(1688) Historia general de las Conquistas del Nuevo Reyno de Gra 1881 nada. Bogotá, Ed. Medardo Rivas.

FLOREZ OCARIZ, Juan

1953-55 Geneaologías del Nuevo Reino de Granada. 2a. edición. Bogotá, Imprenta de la Biblioteca Nacional.

JIJON Y CAAMAÑO, Jacinto

1936-38 Sebastián de Belalcázar. 2 tomos. Quito, Imprenta del Clero.

LAET, Johannes de 1640

L'histoire du nouveau monde ou description des Indes Occidentales. Traducción de la edición de 1625 . Leyde.

PIEDRAHITA, Diógenes

1954 Historia de Toro. 2a. edición. Cali, Imprenta Departamen tal.

SIMON, Fr. Pedro 1882

Noticias Historiales de las conquistas de Tierra Firme en las Indias Occidentales. (1626). 5 tomos. Bogotá, Imprenta de Medardo Rivas.

TASCON, Tulio Enrique

1924 La Conquista de Buga. Buga, Tipografia Colombia.

TRIMBORN, Hermann

1954 Pascual de Andagoya: Ein Mensch erlebt die Conquista. Hamburg, Gram, de Gruyter \& Co.

\section{ZAMORA, Fr. Alonso de}

1945

Historia de la Provincia de San Antonino del Nuevo Reino de Granada. 2a. edición, Biblioteca Popular de Cultura Colombiana. Bogotá, Ministerio de Educación.

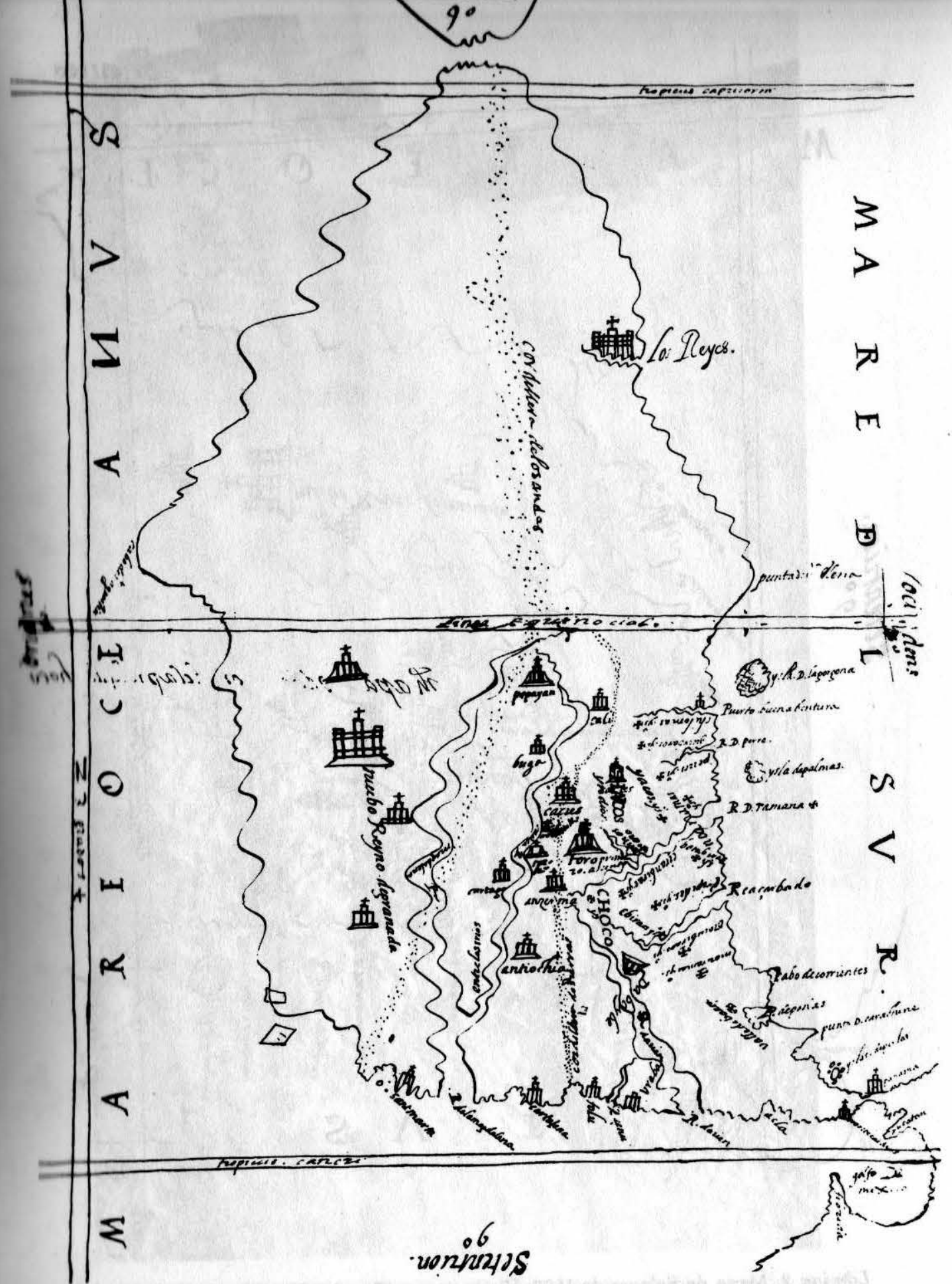

Lámina 1. Mapa que hizo Melchior de Salazar, ex gobernador del Chocó. Fechado 15 de abril de 1596. (Archivo de Indias, Sección Mapas y Planos) 

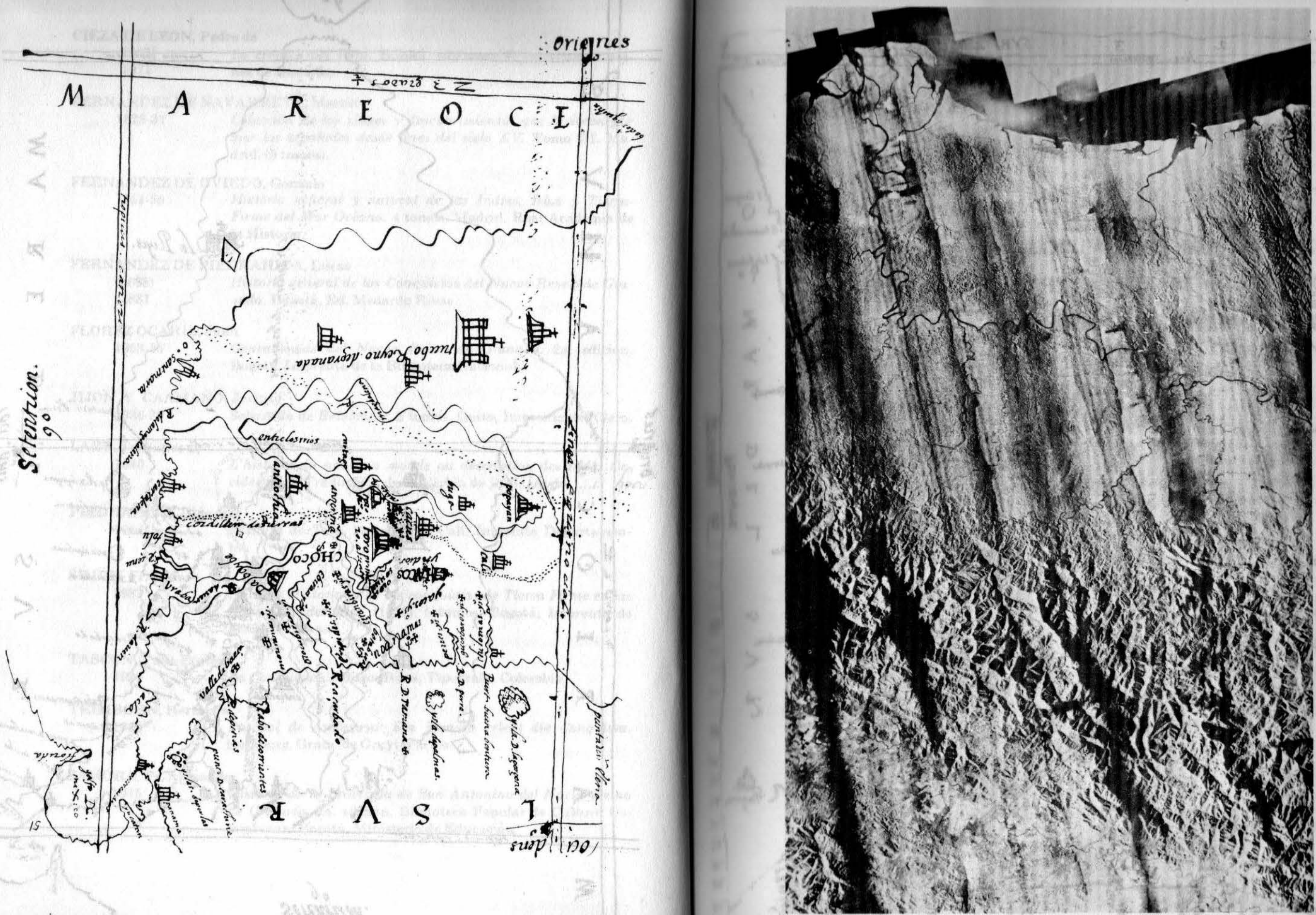

Lámina 2. Mapa de Salazar de 1596: Visión etnográfica del Chocó meridional. (A

ámina 5. Radar-foto: Mosaico en que se muestra la parte central y meridional de Alto Chocó, con el sector correspondiente del Valle del Cauca. (Instituto Geográfico 


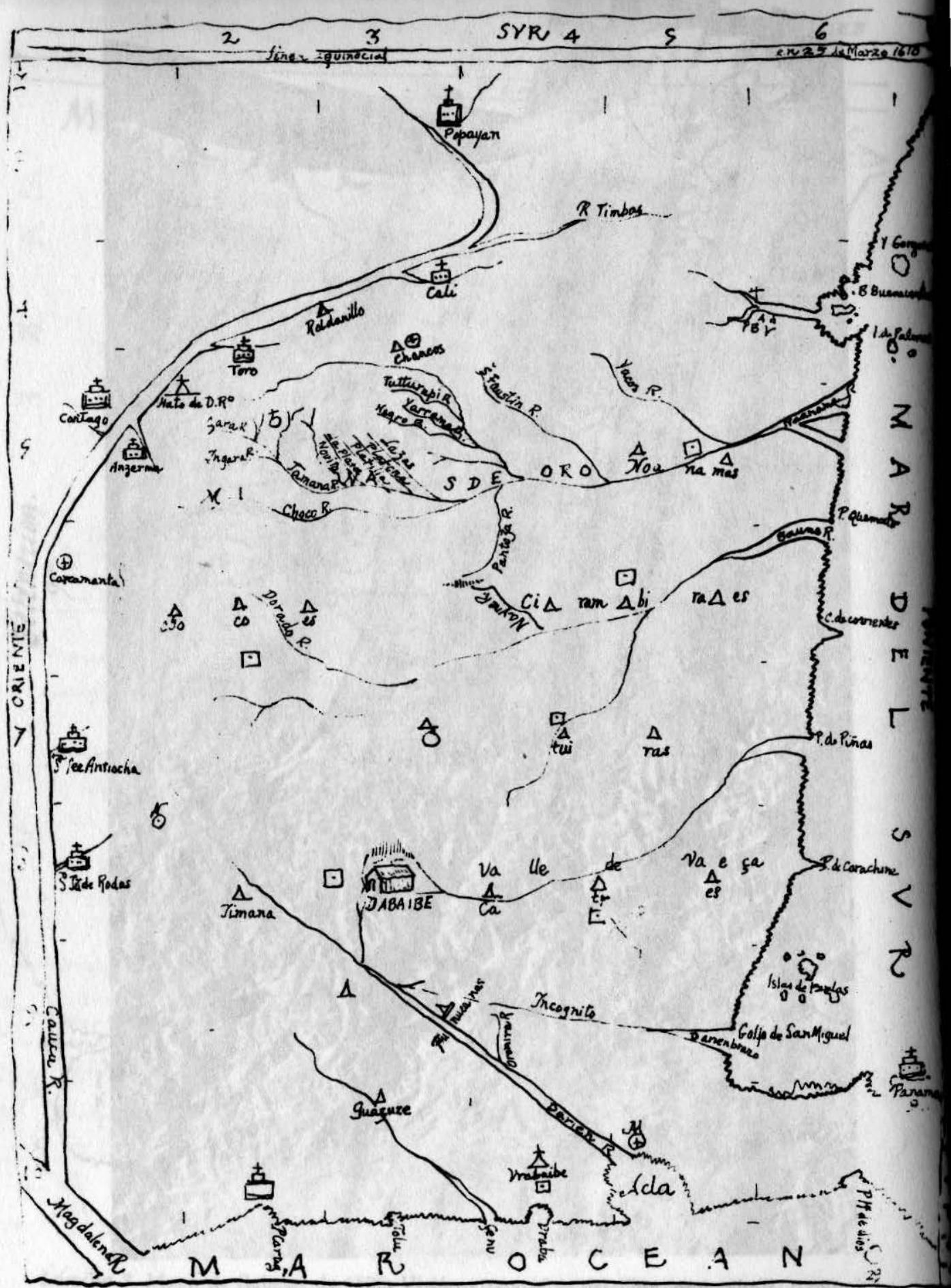

Lámina 6. Mapa del Chocó, dibujado en 1610 y enviado al Rey por el gobernador Sarmiento de Sotomayor (AGI, Sección mapas y planos: Panamá 29). 